Tropical Journal of Pharmaceutical Research September 2015; 14 (9): 1691-1694

ISSN: 1596-5996 (print); 1596-9827 (electronic)

(C) Pharmacotherapy Group, Faculty of Pharmacy, University of Benin, Benin City, 300001 Nigeria.

All rights reserved.

Available online at http://www.tjpr.org

Original Research Article

http://dx.doi.org/10.4314/tjpr.v14i9.21

\title{
Application of 99mTc-DTPA Radiotracer in Persian Cat's Renal Scintigraphy
}

\author{
Gholamreza Assadnassab ${ }^{1 *}$ and Shahram Dabiri Oskoei ${ }^{2}$ \\ ${ }^{1}$ Department of Clinical Science, Faculty of Veterinary Medicine, ${ }^{2}$ Department of Nuclear Medicine, Tabriz University of Medical \\ Sciences \\ *For correspondence: Email: assadnassabgh@iaut.ac.ir; Tel: +989144121145
}

\begin{abstract}
Purpose: To evaluate the suitability of ${ }^{99 m} T c-D T P A$ as a radiotracer in Persian cat's renal scintigraphy. Methods: twelve adult healthy Persian cats were selected. For scintigraphy, the animals were anesthetized and ${ }^{99 m}$ TC-DTPA was injected via the femoral vein as a bolus at a dose of $1.5 \mathrm{mCi}$. Immediately after intravenous injection of radiotracer, scintigraphic operation was conducted on the renal organ. dministration of the radioisotope and accumulation of radioisotope in the tissues was monitored by specific imaging theemanating

Results: Distinct scintigraphic scans were obtained using ${ }^{99 m}$ TC-DTPA. Visual comparison of the scans indicates that there was no significant difference in the accumulation of radiotracer. In dynamic scans, symmetric and concurrent distribution of ${ }^{99 m}$ TC-DTPA in the kidney was observed. Conclusion: The results show that the radiopharmaceutical ${ }^{99 m}$ TC-DTPA is suitable for use in Persian cat's renal scintigraphy, and this makes it potentially useful in research and clinical practice.
\end{abstract}

Keywords: Kidney, Persian cat, Radiotracer, Scintigraphy, Technetium-99m diethylene triamine pentacaetic acid ${ }^{99 m}$ Tc-DTPA)

Tropical Journal of Pharmaceutical Research is indexed by Science Citation Index (SciSearch), Scopus, International Pharmaceutical Abstract, Chemical Abstracts, Embase, Index Copernicus, EBSCO, African Index Medicus, JournalSeek, Journal Citation Reports/Science Edition, Directory of Open Access Journals (DOAJ), African Journal Online, Bioline International, Open-J-Gate and Pharmacy Abstracts

\section{INTRODUCTION}

Renal scintigraphy, also known as renal scanning, refers to several examinations using radioisotopes that evaluate the function and anatomy of the kidneys. Renal scintigraphy is one of many imaging methods used to evaluate the kidneys. Different types of renal scans are used to examine different aspects of the kidneys, however; these procedures involve the injection of radioactive substance that emits a tiny amount of radioactivity. The radiotracer accumulates differently in kinds of tissue and it can help physicians determine diagnosis.

Renal scintigraphy can also be used to evaluate pathology of the kidney $[1,2]$. In this technique, a radioactive substance such as technetium-99m is mixed with special chelating agents. Technetium$99 \mathrm{~m}$ is a metastable nuclear isomer of technetium-99, symbolized as ${ }^{99 \mathrm{~m}} \mathrm{Tc}$, making it the most commonly used medical radioisotope. Technetium-99m when used as a radioactive tracer can be detected in the body by medical equipment (gamma camera) [3,4].

Various intermediate chelating agents labeled with technetium-99m are used for renal scintigraphy, the most commonly used agent being ${ }^{99 m}$ Tc-DTPA (Technetium-99m diethylene triamine pentacaetic acid). Also other agents as ${ }^{99 m}$ Tc-labelled by MAG3 (mercapto acetyl triglycine), EC (ethyl cysteine), 131-lodine labelled OIH (ortho iodo hippurate) can be used 
[2,3]. After injection of radiotracer into the venous system, this compound is excreted by the kidneys and its progress through the renal system can be tracked with a gamma camera. DTPA is a kind of substance called a chelating agent. Chelating agents work by binding and holding on to radioactive materials or poisons that get into the body [2-4].

This study was aimed to determine the safety and suitability of ${ }^{99 m}$ Tc-DTPA for use in the scintigraphy of Persian feline kidney.

\section{EXPERIMENTAL}

\section{Instruments and materials}

A double-detector ADAC Gama camera (Vertex model, Philips Inc.) and Capintec (CRC-5 model, Capintec, USA) dose calibrator machine were used. These apparatus were calibrated and specially designed software was used. DTPA kit (Kavoshyar, Iran) was obtained from Iran Nuclear Research Center. ${ }^{99 \mathrm{~m}}$ Technetium milked from molybdenum-technetium generator was prepared and confirmed by the Atomic Energy Organization of Iran.

\section{Animals}

Twelve adult apparently healthy Persian cats were selected. Blood examinations such as Creatinine, Bun, CBC and clinical examinations were done for assurance of kidneys normality. Animals were housed in standard polypropylene cages at a temperature of $24 \pm 3{ }^{\circ} \mathrm{C}$, with free access to food and water. Procedures were carried out under the Ethical Committee guideline as "Principles of Laboratory Animal Care" (accordance with National Institutes of Health Publication No. 85-23, 1985) in Faculty of Veterinary Medicine, Tabriz Branch, Islamic Azad University, Tabriz, Iran [5,6].

\section{Functional method}

${ }^{99 m}$ Tc was milked from molybdenum-technetium generator and then added to diethylene triamine pentacaetic acid (DTPA) kit. After mixing the kit containing ${ }^{99 \mathrm{~m}} \mathrm{Tc}-\mathrm{DTPA}, 1.5 \mathrm{mCi}$ from this material was measured by dose calibrator machine in an insulin syringe. For scintigraphy, animals were anesthetized and positioned on their backs. Scintillator of machine was set under the table near the kidneys. Before injection of the radiopharmaceutical agent, the test scintigraphic studies from animal and environment were done $[2,3]$.
Thereafter, ${ }^{99 \mathrm{~m}} \mathrm{TC}$-DTPA was injected into the femoral vein as bolus at a dose of $1.5 \mathrm{mCi}$. Immediately after rapid intravenous injection of radioactive agent, imaging was commenced. Secondary activity of the syringe after injection was measured by a dose calibrating machine. During the action, effort was careful made to ensure that the scanning process was not disrupted $[1,3]$.

Animals were anesthetized with ketamine (10 $\mathrm{mg} / \mathrm{kg}$, Alfasan, Woerden, Holland) as main drug and acepromazine $(0.05 \mathrm{mg} / \mathrm{kg}$, Alfasan, Woerden, Holland) as pre-anesthetic drug [7]. For better imaging, the animal's injection area was covered with a lead guard. Immediately after injection, dynamic scanning was commenced. The computer program was set until images of angiophase at $1 \mathrm{~min}$ and other images were scanned in subsequent periods. Total duration of a cat scan was $30 \mathrm{~min}$ in renal nuclear imaging. The scans were compared with visual models $[2,8]$.

\section{RESULTS}

Suitable representative scintigraphic scans were obtained by ${ }^{99 \mathrm{~m}} \mathrm{Tc}$-DTPA radiotracer and the images show the special distribution of the radiopharmaceutical agents. In visual comparison of scans, no significant difference in accumulation of radiotracer was observed. In dynamic scans, symmetric and concurrent passage of ${ }^{99 \mathrm{~m}}$ Tc-DTPA from kidneys were seen.

Figure 1 shows accumulation of ${ }^{99 m}$ TC-DTPA in Persian cat's body. Figure 2 shows a sample of captured dynamic scans in different passing time of ${ }^{99 m}$ TC-DTPA. The symmetric accumulation of radiotracer in the right and the left kidneys was observed in these animals.

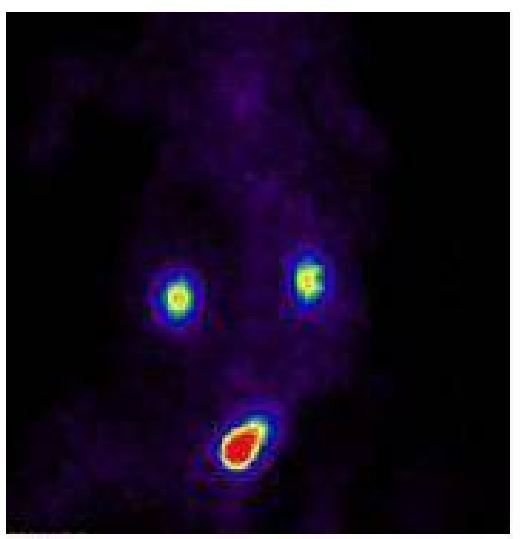

Figure 1: Accumulation of ${ }^{99 m}$ TC-DTPA in a Persian cat body 


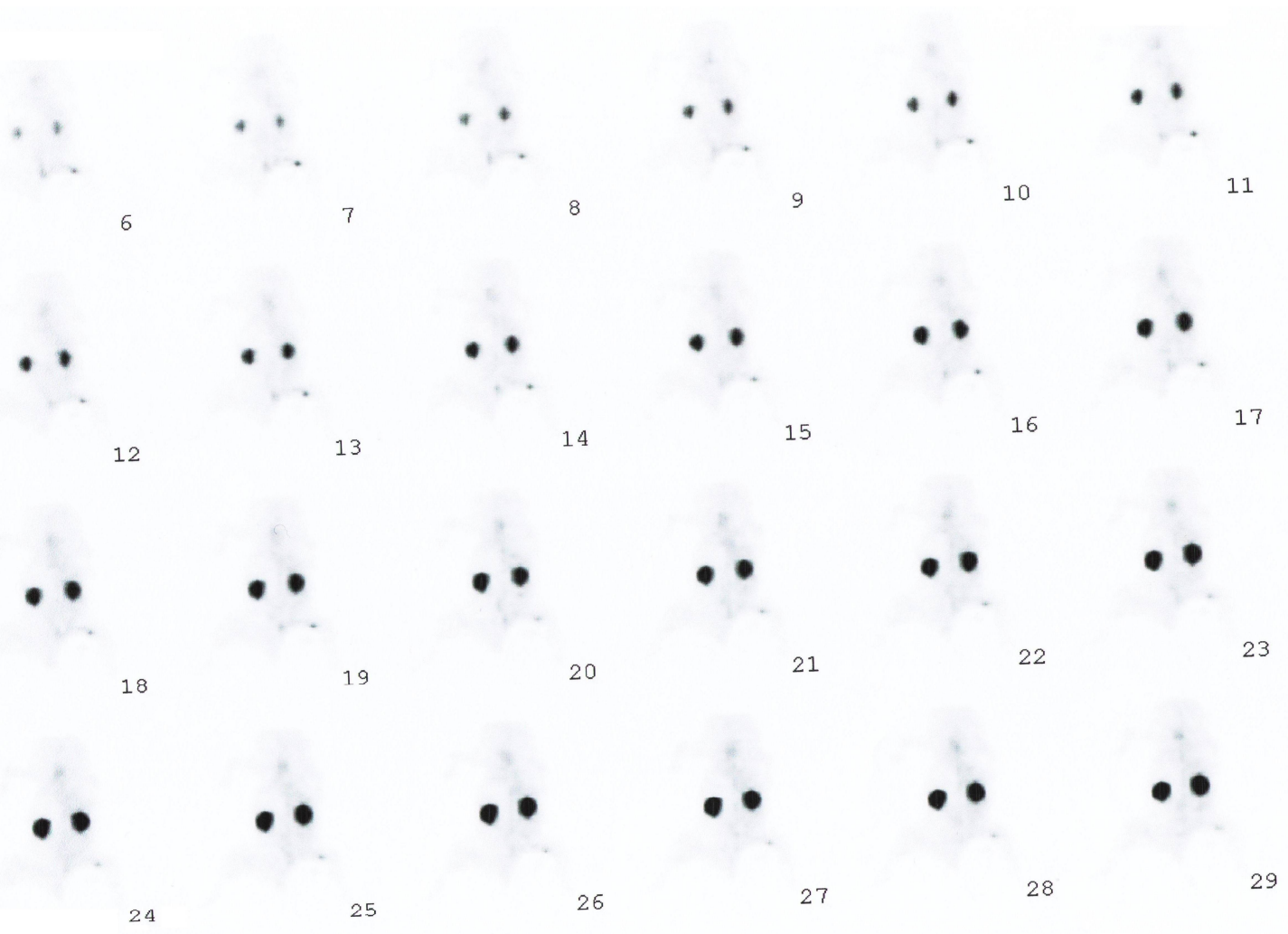

Figure 2: Sample of captured dynamic scans in different passing time of ${ }^{99 m}$ TC-DTPA

\section{DISCUSSION}

Renal scintigraphic imaging is very important in nuclear medicine. Renal disorders associated with the excretion of the kidneys, renal tubular failures and failures associated with the renal perfusion can be detected by scintigraphy. With this technique, the structural composition of the kidney and the physiological functions of the kidneys can be revealed. Kidneys are one of the very important body organs, for example, they excrete toxins and maintain body water. Most severe diseases of the kidney can be detected by this technique $[1,2,9,10]$.

Scintigraphic images show the distribution of radiopharmaceutical agents such as ${ }^{99 \mathrm{~m}} \mathrm{TC}$ DTPA. Complications such as non-symmetric forms of kidneys, delayed absorption of radioactive material in the pelvis and uniform parenchymal may be important in diagnosis. Renal scintigraphy which uses radiopharmaceutical agent cannot attach to the protein and are not secreted or absorbed by the tubules. ${ }^{99 m}$ TC-DTPA possesses the above mentioned properties, and can be tracked by gamma cameras in the stage of accumulating a sufficient number of gamma ray photons $[3,11]$.

It is possible to detect size, shape and position of the kidneys by radionuclide imaging with ${ }^{99 \mathrm{~m}} \mathrm{TC}$ DTPA. Scintigraphy has been proposed and used in evaluating the functional and physiological activities of kidneys $[3,8]$. Scintigraphy is used in animals especially in cats $[8,12-15]$. Renal scintigraphy is carried out in cats for many purposes. Our results are accordance with previous studies on renal scintigraphy in cat $[8,15] .{ }^{99 \mathrm{~m}} \mathrm{Tc}$-DTPA has been used in kidney scintigraphy [3,11]. In many studies, ${ }^{99 m}$ Tc-DTPA was used in cat diuretic renal scintigraphy in normal cats and those with nephroureterolithiasis and the results were found to be similar $[8,15]$.

In the present study, radiotracer used is the same as that used in some studies [8-10]. The reports of side effects when this radiopharmaceutical was employed in some studies, such as kidney failure, allergic reactions and fatal side effects, were not observed in the present study.

In this study, the radioactive count of the right kidney can be compared with that of the left kidney. Renal scintigraphy revealed the anatomical structure and physiological functions of the kidneys as reported previously [8]. With the accumulation of ${ }^{95 \mathrm{~m}}$ TC-DTPA in Persian cats body in the scanned images, it seems that scintigraphy can identify certain diseases of the kidney, thus providing supplementary information for accurate diagnosis $[2,13,15]$. 
The investigation revealed that scintigraphy of Persian cat kidneys with ${ }^{99 m}$ TC-DTPA has many similarities with human kidney scintigraphy [1-3]. Computer programs such as those used for scanning and collecting images, as well as for drawing ROls can also applied to Persian cat without any problems. Evaluation of the Persian cat kidney scans revealed that detection of the radioactive agents was achievable using the computer programs of the gamma cameras. Illustration of the cat's kidney ROls was achievable by computer programs, and application of this technique in Persian cats was achieved just like for human kidney $[1,3,14]$.

Computer configurations for execution and time steps of scintigraphy operations in Persian cats are similar to those done in human. Scintigraphy is considered a useful method in diagnostic imaging and veterinary science. This study shows also that animals like cat can be used in medical research and veterinary medicine as a specific animal model used in nuclear medicine and drug research.

\section{CONCLUSION}

${ }^{99 \mathrm{~m}}$ Tc-DTPA radiotracer is suitable for use in cat's renal scintigraphy, and is thus potentially useful in research and clinical practice. Side effects are not likely to be observed with this radiopharmaceutical.

\section{ACKNOWLEDGEMENT}

The authors would like to thank Tabriz Branch, Islamic Azad University, Research Department for the financial support of this work based on a research project contract, and Dr Dabiri Nuclear Medicine Center for help in scintigraphy operations.

\section{REFERENCES}

1. Blaufox M. Procedures of choice in renal nuclear medicine. J Nucl Med 1991; 32: 1301-1309.

2. Henkink R, Boles M, Dillehay G, Eds. Nuclear Medicine, St Louis: Mosby - Year Book; 1996; pp 1055-1090.
3. Mettler F, Ed. Essentials of Nuclear Medicinine Imaging. 4th edn. Philadelphia: Saunders; 1998; pp 203- 277.

4. Zolle I, Ed. Technetium-99m Pharmaceuticals: Preparation and Quality Control in Nuclear Medicine. Berlin: Springer; 2007; pp 10, 61-65, 300-303.

5. Guide for the Care and Use of Laboratory Animals. Washington, DC: Government, Printing Office 1985; NIH publication 85-23.

6. Hallenbeck JM, Dutka AJ, Kochanek PM, Siren $A$, Pezeshkpour GH, Feuerstein G. Stroke risk factors prepare rat brainstem tissues for modified local Shwartzman reaction. Stroke 1988; 19: 863-869.

7. Hall LW, Clarke KW, Trim CM, Eds. Veterinary anesthesia. 10th edn, London: W.B. Saunders; 1998; pp 463-477.

8. Hecht S, Lane IF, Daniel GB, Orandi F, Sharp DE. Diuretic renal scintigraphy in normal cats. Vet Radiol Ultrasound 2008; 49(6): 589-594.

9. Bowen J, Sharma H, Gough DC. Chronic hydronephrosis: renographic drainage patterns and renal morphology in an animal model. Br J Urol 1994; 74(1): 26-30.

10. Wilkinson SP, Bernardi M, Pearce PC, Britton KE, Brown NJ, Poston L, Clarke M, Jenner R, Williams $R$. Validation of transit renography for the determination of the intrarenal distribution of plasma flow: comparison with the microsphere method in the anaesthetized rabbit and pig. Clin Sci Mol Med 1978; 55(3): 277-283.

11. Awuawanne, A, Ed. The hand book at radiopharmaceauticals.1th edn. London: Champan and hall; 1995; pp 102-144.

12. Chow PL, Stout $D B$, Komisopoulou E, Chatziioannou AF. $A$ method of image registration for small animal, multi-modality imaging. Phys Med Biol 2006; 21; 51(2): 379-390.

13. Annet L, Hermoye L, Peeters F, Jamar F, Dehoux JP. Glomerular filtration rate: assessment with dynamic contrast-enhanced MRI and a cortical-compartment model in the rabbit kidney. Van Beers BE J Magn Reson Imaging 2004; 20(5): 843-849.

14. Barthez PY, Schaafsma IA, Pollak YW. Multimodality image fusion to facilitate anatomic localization of 99mTC-pertechnetate uptake in the feline head. Vet Radiol Ultrasound 2006; 47(5): 503-506.

15. Hecht S, Lawson SM, Lane IF, Sharp DE, Daniel GB. 99mTc-DTPA diuretic renal scintigraphy in cats with nephroureterolithiasis. J Feline Med Surg 2010; 12(6): 423-230 